\title{
The Influence of China's Population Aging on Economic Growth
}

\author{
Guangtao Zhou \\ Shandong Xiehe University, Jinan, China \\ zhouguangtao@126.com
}

Keywords: Population Aging; Economic Growth; Labor

\begin{abstract}
Population aging is one of the common problems facing the world today and has become an important factor restricting economic growth. China's population aging shows basic characteristics such as rapid growth of aging, "aging before getting rich", and the number of venerable aged population increasing. The impact of population aging on economic growth is mainly reflected in the reduction of supply of working-age labor, the reduction of labor productivity, the blocking of upgrades of industrial structure, and the reduction of the efficiency of investment in physical and human capital, etc. It is suggested to vigorously develop aging industries, improve labor efficiency and quality, optimize and upgrade industrial structure, and accelerate the flow of labor resources, so as to cope with the problem of population aging in China and promote rapid economic growth.
\end{abstract}

\section{The basic status of China's aging population}

\subsection{The rapid development of population aging}

The China Statistical Yearbook (2017) tells that the total population of China at the end of 2016 was 1.38 billion, ranking first in the world and the second largest economy in the world. However, with the stability and rapid development of the economy, China's population is aging. In 2016, the total population of China aged 65 and over reached 150.3 million, accounting for $10.8 \%$ of the country's total population. It is known that China's population is rapidly aging and is expected to grow more rapidly. The number of population at 65-years-old and above in China is also the largest in the world. The speed of population aging in China is following Japan which is the fastest aging country (24 years), higher than the United Kingdom (45 years), Switzerland (50 years), the United States (65 years), and France (115 years).

\subsection{The status of "aging before getting rich" is obvious}

In developed countries such as the United States, Japan, and the United Kingdom, when the population is aging, its economy was already at a relatively developed level. When China entered the period of population aging, comparing with other countries, the level of economic development (per capita GDP) was still at a low level. As a developing country, the aging in China shows a state of "aging before getting rich". In Japan, for example, when the proportion of the elderly population aged 65 and over is $7 \%, 10 \%$, and 14\% respectively, the corresponding per capita GDP was as high as USD 1967.64, USD 11,335.32, and USD 38,555.49 (Zheng, Lin \& Chen, 2014). Although China has become the second largest economy, the per capita GDP of China is far behind Japan. As early as 2000, the proportion of the population aged 65 years and above of the total Chinese population reached aging dividing line as 7\%, the per capita GDP was only USD 956, and there was a big gap comparing with Japan (Zhai \& Zheng, 2016).

\subsection{The growth of the venerable aged population is faster}

The venerable age defined in this article refers to people aged 80 years and older. With the significant improvement in medical treatment and care, the average life expectancy of human beings has increased. China currently accounts for a large proportion of the elderly population aged 65 and over, and the proportion of elderly people aged 80 and over is rising. According to the 
statistics of the National Bureau of Statistics (2016), at the end of 2016, the total number of elderly people aged 80 and over in China reached 24,754,300, accounting for $16.5 \%$ of the elderly population in the same period, indicating that China's aging is increasing.

\section{The main impact of China's aging population on economic growth}

\subsection{Reduction of the supply of working-age labor}

There are many factors that promote economic growth, and labor is one of the most important factors. China's economy has developed rapidly in recent years and has become the world's second largest economy. A large part of this achievement can be attributed to the abundant labor force in China. China's economic development is mainly based on labor-intensive industries, which requires a large amount of labor to support. The labor force is a very important factor to realize the expansion of reproduction as soon as possible. With the population is aging, the labor force is getting less and less, which is not conducive to the development of a country's economy. It is precisely because of the aging of the population that the decline in the working-age population has become a trend that will slow down economic growth, which has been verified in developed countries such as Japan and France. Relevant data show that the aging population will cause China's labor force to decline year by year and the labor force rate will fall to 57\% in 2030 (Zeng, 2014). In order to minimize the economic impact of population aging, China needs to transform labor-intensive industries and upgrade industrial structure.

\subsection{Reduced labor productivity}

The trend of aging population in China has become increasingly serious. With the growing number of elderly people, the number of working-age population will be less and less, the average productivity of society will be reduced, and even the average labor quality will be affected. Wang (2017) analyzes the impact of aging on China's economic growth by dividing the labor force into three parts: the young labor force, the middle-aged labor force, and the old-age labor force. When a country's old-age labor force is large, then the ration of elderly labor population of total labor force will rise. It is well known that the working conditions and efficiency of the elderly will be affected by physical conditions and the quality of the elderly labor is not as good as that of younger group. Therefore, the average production efficiency of the society will be affected, thus affecting economic growth.

\subsection{The optimization and upgrading of industrial structure is blocked}

China is currently in a critical period of economic transformation and needs to continuously upgrade its industrial structure. With the increasing number of elderly people in China, the degree of aging is deepening, the economic structure is changing, and the optimization and upgrading of industrial structure must coordinate the balance between economy and population structure. The accelerated development of population aging will also have a certain negative impact on the upgrading of industrial institutions, which is not conducive to industrial layout and will affect the healthy development of China's economy in the long run (Zhai \& Zheng, 2016). The upgrading of industrial institutions and the development of emerging industries require the cooperation of a large number of laborers. The elderly labor force is more conservative, less accepting new things, and less willing to accept regional transfers, which will be detrimental to industrial upgrading and new industrial transfer.

\subsection{Reduced efficiency of investment in materials and human capital}

The two main directions of capital investment are material capital investment and human capital investment, which is also the main flow of investment and can promote the sustainable development of the economy. As the population aging increases, among the total labor force, the proportion of the elderly labor force rises. Because the physical function of the elderly labor force is declining, and learning ability and work efficiency cannot be the same as that of young group, there will be a slight poor ability of the elderly labor force to master new technologies and new products, which is 
not conducive to the promotion of new technologies and products; on the other hand, The elderly workforce is slow to learn new professional knowledge, which reduces the company's expectations for employee training. These conditions will affect the average production efficiency of the society, thus affecting the steady growth of the economy (Wang, 2017).

\section{Countermeasures for coping with population aging to promote economic growth}

\subsection{Vigorously develop the aging industry}

China's vigorous development of the aging industry should start from three aspects. First, continuously encouragement of private capital. The government should encourage and guide the flow of private capital to the aging industry from the policy, grant financial, fiscal and taxation policies to the aging industry in terms of loans, subsidies, tax cuts, etc., and regulate the use of private capital. Second, to cultivate the market for aged products. Besides providing simple food necessities for the elderly, such as food, clothing, housing and transportation, it is also necessary to vigorously cultivate and develop elderly products such as old-age care, health care, recreation, medical care, and education consultation that can reflect intelligence and humanity. With the supply-side structural reform as the main line, it is easy to actively develop the market for elderly products, continuously increase the supply of old-age products, thereby promoting demand growth and economic growth. On the third, to vigorously develop the modern service industry for the elderly. It is necessary to establish an elderly service center in all cities across the country, and to maintain a comprehensive network of service development partnerships related to the elderly population, and to develop services that are suitable for the elderly population.

\subsection{Improve labor efficiency and quality}

The most important thing to improve labor efficiency and quality is to increase investment in human capital. The main focus should be on two aspects. First, it is to increase investment in education. It is expected to invest in a big scale to cultivate talents, gradually improve the quality of laborers of all people, expand the knowledge reserves of laborers, improve the accumulation of human capital, increase the productivity of unit labor by raising the level of basic education of the masses, thereby expanding reinvestment and promoting the development of production cycle. On the second, it is to develop and take full use of the elderly population resources. By continuously expanding the number of existing labor force, it is possible to appropriately transfer the strong elderly labor force to a high-quality workforce. For example, companies can re-hire the excellent retired cadres or workers and provide them with skills training, which can make human capital costs reduced obviously, and more importantly, it will enable aged people to realize their social values and to increase their love for work and yearning for life.

\subsection{Optimizing and upgrading the industrial structure}

The economic growth, narrowly speaking, refers only to quantitative growth, while the broad meaning of economic growth is reflected in the optimization and upgrading of industrial structure. While China facing severe population aging problem, the number of working-age population is declining. To maintain long-term sustained economic growth, it is necessary to rationally optimize and upgrade the industrial structure. The upgrading of industrial structure can reduce the number of dependent labors to a certain extent and drive economic transformation and upgrading. China's demographic dividend is slowly disappearing, labor supply and non-comprehensive advantages, labor-intensive industries are gradually unable to adapt to the development of high-tech industries, resource-intensive and labor-saving industries are growing, and economic sustainable development depends more on advanced technology, and the continuous optimization and upgrading of the industrial structure can cope with the problem of China's aging population and promote healthy and sustainable economic development.

\subsection{Accelerating the flow of labor resources}

China's economic development is relatively unbalanced. This is not only reflected in the 
differences between the east and the west, but also in the urban-rural differences. China's household registration system has widened the gap between urban and rural areas. The rural population enjoys far less benefits than the urban population. There is no equal opportunity in medical care, health, employment, etc. These have affected the process of urban-rural integration. There is no overall planning and optimization of resources, which reduces the productivity of labor and has a negative impact on economic development. China's important economic goal is to maintain economic growth, but the increasing aging of the population has also led to a decline in the average production efficiency of the society, which has affected the steady growth of the economy. Just as the two sides of the coin, the aging of the population has brought opportunities and challenges to China's economic development. China can take the opportunity to develop the aging industry, to actively explore the market for elderly products, providing high quality services for the elderly, and find new economic growth points from the populating aging society.

\section{Acknowledgments}

The work described in this paper was fully supported by a grant from the Humanities and Social Sciences Research Program in Universities \& Colleges of Shandong Province 2016 (No. J16WE08).

\section{References}

[1] National Bureau of Statistics of China. (2016). China Statistical Yearbook. Beijing: China Statistics Press.

[2] National Bureau of Statistics of China. (2017). China Statistical Yearbook. Beijing: China Statistics Press.

[3] Wang, W. (2017). Population aging, Adjustment of Birth Policy and China's Economic Growth. Economics, (1), 67-96.

[4] Zeng, G.X. (2014). New Characteristics of China's Population Aging. Journal of Chongqing University, 20(2), 136-139.

[5] Zhai, Z.W. \& Zheng, R.Z. (2016). On the Relationship between Population Aging and Macroeconomics. Population Research, 40(2), 75-87.

[6] Zheng, W., Lin, S.J. \& Chen, K. (2014). The characteristic trend of China's aging population and its potential impact on economic growth. Quantitative Economics Research, 31(8), 3-20. 